\title{
Evaluation of patient satisfaction in hospitals in China 2003-2013: A national longitudinal analysis of population-based survey data
}

Daisheng Tang

Beijing Jiaotong University

Ying Lian

Beijing Jiaotong University

Xuefan Dong ( $\square$ langshusheng@163.com )

Beijing Jiaotong University https://orcid.org/0000-0002-2318-4805

Research article

Keywords: Patient satisfaction; Healthcare; Health reform; China; Trends

Posted Date: August 23rd, 2019

DOl: https://doi.org/10.21203/rs.2.13535/v1

License: (c) (1) This work is licensed under a Creative Commons Attribution 4.0 International License.

Read Full License 


\section{Abstract}

Understanding the perception of patients towards the quality of hospitals is critical to policy development and improvement. However, there remains a dearth of literature examining the impact of the new health reform launched by China's government in 2009 on the changes of the patient satisfaction. Thus, the aim of this paper was to evaluate long-term trends in patient satisfaction to healthcare providers in China from 2003 to 2013. The data from three rounds $(2003,2008$, and 2013) of the National Health Service Survey. The unsatisfactory rate, hospital satisfaction assessment and the most dissatisfied items for outpatients and inpatients in urban and rural areas in China were considered Percentages changes from 2003 to 2008,2008 to 2013 , and 2003 to 2013 were calculated to descriptively show the trends of patient satisfaction between these 10 years. Chi-square tests regarding the changes of each item between any two years were carried out to evaluate temporal variance. The results reveal a significant overall improvement in the patient satisfaction of both inpatients and outpatients in urban and rural areas in China from 2003 to 2013, especially for the period between 2008 and 2013. However, the percentage of outpatients who dissatisfied with the waiting time for treatment largely increased between 2008 and 2013. In addition, both inpatients and outpatients tended to pay more attention to the service quality and medical expense. With respect to the patient-physician trust relationship, an overall marked improvement could be identified. The findings of this study are unique in presenting the patient satisfaction at the national level in China, which highlight a need to carry out more national actions focusing on the optimization of visiting mechanism, the deduction of medical costs and the improvement of doctors' service and medical quality.

\section{Introduction}

Patient satisfaction is an important outcome to measure the quality of health services [1], and it has attracted the attention of scholars for decades [2,3]. Numerous studies focused on the measure of patient satisfaction with the consideration of different diseases including, but not limited to dermatology [4] and hypertension [5]. In addition, the questionnaire method is widely applied by existing related studies. In this view, how to set variables or how to design questions to comprehensively measure patient satisfaction has been identified as an important aspect. For example, Zimmerman et al. [6] compared the performance of the American Board of Psychiatry and Neurology measure with that of the Clinically Useful Patient Satisfaction Scale in evaluating patient satisfaction, and the latter was proven stronger. Graham [7] suggested that simply asking patients who had completed care whether they would undergo treatment again was not a reasonable choice but was rather a more complex one that requires diversified consideration, in which the expectation of patients plays an important role. Trust in the physician and in the medical institution is also seen as a vital property of patient satisfaction [8]. In fact, most patients can only depend on the advice of doctors in choosing the treatment plan because they generally lack professional knowledge to judge the scientificality and correctness of the plan. From this point of view, medical services refer to credence goods, which can be defined as the products that consumers cannot assess the quality of even a long time after the purchase [9]. Conversely, most other products can be 
viewed as experience goods [10], such as clothes, cars, and electronics. Experience goods can be generally defined as products that consumers can assess the quality of once they are consumed or serviced [11]. The main difference between credence goods and experience goods is the degree of the informational asymmetry between sellers and consumers. With respect to the relationship between patients and hospitals or doctors, a typical example of credence goods, this asymmetry may cause some cheating behaviors, such as offering insufficient and unnecessary medical services and charging excessive costs for a given medical service. Moreover, for experience goods, return policies that can reduce the risk of consumers' irrational buying behavior to a large extent are widely provided. That is, the reversibility characteristic is contained in this selling-buying process. However, credence goods, such as medical services, have no return policies, and the trading process is irreversible. For example, surgery for patients cannot be "returned," although it can be officially proved to be inappropriate or completely wrong after the service. These effects enable patients to be more cautious and thoughtful when selecting healthcare providers, especially the high risk-aversion ones and those that frequently cause workplace violence events in hospitals [12]. Improving the patient-physician trust seems to be the only effective way to reduce this kind of risk.

China has the largest population in the world. Healthcare services have been identified as a key issue in its population's well-being [13]. According to the National Health and Family Planning Commission of the People's Republic of China, the number of outpatients in medical and health institutions between January and November 2018 reached 75.4 billion, in which those in hospitals accounted for $42.84 \%$. The number of hospitals increased to 32,476 since the end of November 2018. For the Chinese government, how to manage and improve such a large healthcare market is a great challenge. Therefore, understanding the state of patient satisfaction and what patients are most concerned about from a national perspective is necessary. However, little research has been conducted to evaluate the quality of healthcare institutions with respect to the patients, and most of these studies focused only on some particular regions $[14,15]$ or particular diseases [16]. Consequently, the perception and expectation of patients of Chinese hospitals are still poorly understood. This limitation is largely due to the scarce data, which are caused by the deficiency in medical data sharing, consolidation, and standardization processes in China and the special sensitivity feature of the medical data.

In 2009, the Chinese government implemented a new health reform to solve the difficulty and expensive medical treatment problems and to improve patient satisfaction [17]. Understanding the performance of this reform from the patients' perspective is important. In this field, Yan et al. investigated the effects of the new health reform on patient satisfaction by comparing urban and rural areas [18]. Wang et al. identified the factors affecting patients in terms of China's public hospitals after the new health reform [19]. However, only 40 county-level hospitals in two provinces of China and 5 public hospitals in Jiangsu Province of China were considered by these two papers, respectively, and thus these studies could not 
present a national assessment analysis. In addition, with respect to patient-physician trust, a decreasing trend was identified by previous studies in China's healthcare market before the implementation of the new health reform [20,21], and this trend was mainly caused by the persistent imbalance between the expectation of the public and the poor effects of China's health policy. Consequently, the satisfaction degree of patients seemed to be continuously low in that period of time [20]. However, the number of studies focusing on this trust relationship after the new health reform is relatively few, and most of them paid more attention to the influencing factors [21] and improvement strategies [22] than to the effect of the new health reform on the changes in the patient trust degree. Moreover, there is also a shortage of the use of national survey data in the existing literature. As a result, the current state of this trust relationship is still poorly understood.

The overall aim of this study was to examine patient satisfaction in hospitals in the urban and rural areas in China over the last 10 years and to evaluate the effect of the new health reform on this issue from national and multidimensional perspectives by considering the quality of medical staffs, medical services, treatment environments, and patient-physician trust. The expectation of patients, which was considered as an important factor in the improvement of patient satisfaction [7], in the future development of hospitals in China was also considered.

\section{Methods}

\subsection{Study design}

This study comprised a longitudinal analysis of patient satisfaction in hospitals in China using the National Health Service Survey (NHSS). NHSS is a population-based, nationally representative survey that collects information on health service demand and utilization every five years in China [23]. This study was organized in compliance with the REporting of studies Conducted using Observational Routinely collected Data Statement.

\subsection{Data source}

In total, NHSS underwent five rounds conducted in 1993, 1998, 2003, 2008, and 2013. In terms of patient satisfaction in hospitals, only the third (2003), fourth (2008), and fifth (2013) round of surveys considered the relevant issues. Thus, these three rounds of surveys were applied in this study.

Three rounds $(2003,2008$, and 2013$)$ of the NHSS were completed using a multi-stage sampling and face-to-face interviewing method [24]. In the patient satisfaction assessment included in the NHSS questionnaires, both the outpatients and the inpatients, two important components of patients, were 
considered. In comparison, outpatients and inpatients have considerable differences [25]. Specifically, the former is less dependent on medical care and has less communication with physicians than the latter. Conversely, inpatients generally spend more time in hospitals and depend more on medical care than outpatients. Some existing studies evaluated and compared the patient satisfaction of these two groups $[25,26]$. Thus, the current study considered the perception of both outpatients and inpatients of hospital satisfaction to show a comprehensive picture. Based on the NHSS data, the two-week outpatients were set as the outpatient group. The structured interview questionnaires were not changed over the three rounds of the NHSS, except for some items that were updated and deleted because of related health policies.

According to relevant health data management regulations, the NHSS can be accessed through the Center for Statistics and Information, National Health and Family Planning Commission of the People's Republic of China.

\subsection{Measures}

Three measures of both outpatients and inpatients were considered in the three rounds of NHSS: unsatisfactory rate, hospital satisfaction assessment, and the most dissatisfying items. The details are shown in Table 1. These three measures reflected the quality of both medical staffs and hospitals and provided a relatively comprehensive assessment to a large extent.

Note that because of the design differences in the NHSS in the different rounds of surveys, the number of options for the hospital satisfaction assessment for the respondents conducted in three rounds was different. Specifically, three options (very good/good, normal, and very bad/bad) were available in 2003 and five options (very good, good, normal, bad, and very bad) in 2008 and 2013. Thus, to conduct a fairly comparative analysis, the values of very good and good, and very bad and bad were respectively summed except "trust degree in the doctor."

\subsection{Statistical analysis}

We estimated the proportion of patient satisfaction of both outpatients and inpatients in the urban and rural areas in China in 2003-2008, 2008-2013, and 2003-2013 by focusing on three aspects, namely, unsatisfactory rate, hospital satisfaction assessment, and most dissatisfying items. Percentage changes were calculated to measure the differences in each item in the three time periods by using the following 
the formula: (percentage in the later year-percentage in the earlier year)/ percentage in the later year $\times 100 \%$.

By following Mathews et al. [27], the comparison of each item between any two years was conducted using chi-square tests to evaluate the temporal changes. All statistics were descriptive and were performed by using Stata 12.1. Statistical significance was defined as $\mathrm{P}<0.05$.

\section{Results}

\subsection{Sample characteristics}

A total of 51,686 outpatients and 40,588 inpatients in 532 counties or districts of China were interviewed over the three rounds of NHSS (Table 2). The proportion of urban residents increased substantially in the NHSS samples from 2008 (25.2\%) to 2013 (49.4\%), indicating the demographic shift in China's population and economic development in that time period [24].

\subsection{Satisfaction of outpatients in hospitals}

\subsubsection{Unsatisfactory rate}

The results for the unsatisfactory rate in 2003, 2008, and 2013 are shown in Figure 1. Across the three surveys, a significant decreasing trend was found in the unsatisfactory proportion during the 10 years, especially in the period of 2008-2013. In particular, the unsatisfactory rate decreased by $3.86 \%, 42.97 \%$, and $45.17 \%$ in $2003 v 2008,2008-2013$, and 2003-2013, respectively. Note that a gap between the urban and rural areas remained during these 10 years.

\subsubsection{Satisfaction assessment}

The satisfaction degree of the outpatients in both urban and rural areas largely improved from a global perspective, especially for the items related to doctors, such as "listing the seriousness of patients' illness." The changes in all items except "interpretation clarity of the treatment" $(P$ value $=0.831)$ are statistically significant. Specifically, the percentages of the "very good/good" option for these two items within the urban and rural groups increased by $24.55 \%, 35.53 \%, 44.40 \%$, and $43.76 \%$, respectively. In terms of "medical treatment environment," a considerable increase was found during the 10 years, especially in 2008-2013, and this increase was more significant in the rural areas. The percentage of rural outpatients who chose "very good/good" increased by $70.73 \%$ in 2008-2013. Moreover, the trust 
degree of outpatients in doctors significantly increased in 2008-2013, especially for those in rural areas. Specifically, the percentage of the option "trust very much" chosen by the outpatients increased by $145.21 \%$ and that by the rural outpatients increased by $208.71 \%$. The percentage of the urban and rural outpatients who selected the option "distrust very much" decreased by $80.67 \%$ and $94.38 \%$, respectively (Table 3).

"Waiting time for treatment" seemingly became worse during these 10 years. Specifically, the percentage of the option "very good/good" decreased from $67.11 \%$ in 2003 to $59.44 \%$ in 2008 and then increased to $63.57 \%$ in 2013 . The changing percentage of this option in $2003-2013$ was $-5.27 \%$. The percentage of the option "very bad/bad" increased by $36.01 \%$ in $2003-2013$ and that for rural outpatients was $27.03 \%$.

\subsubsection{Most dissatisfying item}

The results shown in Table 4 indicate that the changes in the focus of the outpatients on the dissatisfying items are very significant (the calculated P values in 2003-2008, 2008-2013, and 20032013 are all smaller than 0.01). In terms of the details, a contrasting tendency was found in the items "high medical costs" and "poor medical equipment." For the former, the percentage of outpatients who chose "high medical costs" as the most dissatisfying item decreased by $60.47 \%$ in $2003-2008$ and then increased by $103.3 \%$ in $2008-2013$. Specifically, the changing percentage of the outpatients in the rural areas increased by $130.07 \%$. In comparison, the percentage of the interviewed outpatients who considered "poor medical equipment" as the most dissatisfying item increased by $52.22 \%$ in 2003-2008 and then decreased by $94.89 \%$ in 2008-2013. In addition, an increasing early and then a decreasing later tendency was found for the item "cumbersome procedures." A significant decrease was observed for the items "long waiting time for treatment," "unnecessary services," and "fewer drug varieties" (Table 4).

For the items "low medical service level" and "poor service attitude," a marked increase was found in both the urban and rural areas, especially in 2008-2013. In particular, the percentage of outpatients who chose "low medical service level" and "poor service attitude" as the most dissatisfying item increased by $80.75 \%$ and $249.83 \%$ in $2008-2013$, respectively.

In terms of "unreasonable charges," the population in the urban and rural areas showed different results. The percentage of outpatients in the urban areas who were most dissatisfied with this item decreased by 
$20.11 \%$ in $2008-2013$, whereas that of outpatients in the rural areas increased by $106.03 \%$ in that period of time.

\subsection{Satisfaction of inpatients in hospitals}

\subsubsection{Unsatisfactory rate}

A significant decreasing trend was found in the periods of 2003-2008 ( $P$ value $=0.007), 2008-2013$ ( $P$ value $=0.000)$, and $2003-2013(P$ value $=0.000)$. Specifically, the unsatisfactory proportion of the all the inpatients, urban inpatients, and rural inpatients decreased by $41.13 \%, 37.45 \%$, and $47.73 \%$ in $2003-$ 2013 , respectively. This result indicates that the satisfaction level of inpatients was largely improved during these 10 years (Figure 2).

\subsubsection{Satisfaction assessment}

From a global perspective, similar to the satisfaction assessment results for the outpatients, the satisfaction degree of inpatients was largely improved in 2003-2013, especially for the rural populations. Approximately all changes in each item were significant except the "evaluation of the medical treatment environment" item for the urban group in 2008-2013 $\left(X^{2}=3.736\right.$; $P$ value $\left.=0.154\right)$. Specifically, the percentage of the option "very good/good" of "interpretation clarity of the treatment," "listing the seriousness of patients' illness," and "evaluation of medical treatment environment" increased by $13.55 \%$, $24.39 \%$, and $19.94 \%$, respectively, in 2003-2013. Conversely, the percentage of the "very bad/bad" option of the same items decreased by $64.13 \%, 82.74 \%$, and $42.87 \%$, respectively, in the same period. Additionally, the improvement range in 2008-2013 was greater than that in 2003-2008 to a large extent (Table 5).

Moreover, considerable enhancements were found for the items "convenience of querying medical costs" and "convenience of complaint." In terms of "trust degree in the doctor," a significant improvement was found in 2008-2013, especially for rural outpatients. Particularly, the percentage of the population in the urban and rural areas that chose the option "trust very much" increased by $23.41 \%$ and $132.58 \%$, respectively. 
The calculated chi-square test results indicated that the concern of the inpatients regarding the most dissatisfying items was significant during the 10 years (the $P$ values in 2003-2008, 2008-2013, and 2003-2013 for the total, urban, and rural groups are all smaller than 0.01). In the case of "low medical service level" and "poor service attitude," a significant increase was found in these 10 years, and this increasing characteristic was more pronounced in 2008-2013 and in rural areas. In addition, a decreasing early and then increasing later tendency was found in the item "high medical costs," and the items "poor medical equipment" and "cumbersome procedures" showed an inverse changing feature. These findings are similar to those for the outpatients. The percentage of inpatients who considered "unreasonable charges," "long waiting time for treatment," "unnecessary services," or "fewer drug varieties" as the most dissatisfying item decreased by $9.01 \%, 77.51 \%, 2.72 \%$, and $47.08 \%$, respectively, in $20013-$ 2013 (Table 6).

\section{Discussion}

\subsection{Summary of the primary findings}

By using the national population-based survey data, this study evaluated the long-term trends in patient satisfaction in hospitals in both urban and rural areas in China. The following findings were obtained:

(1) Unlike the widely accepted conclusion that patient satisfaction in China is low, as proposed by previous studies using cross-sectional data sets of some particular areas $[13,28]$, this study provided a more comprehensive comparison analysis using national time-series data. The study found that the satisfaction of both inpatients and outpatients was largely improved between 2003 and 2013, especially in the period of 2008-2013. This considerable improvement is mainly attributed to the implementation of the new health reform in 2009 to a large extent.

(2) Patient satisfaction with respect to the issues on hospital management, such as treatment environment, visiting process and drug supply, and doctor service quality, significantly increased during these 10 years. However, the percentage of outpatients who were dissatisfied with the waiting time for treatment largely increased in 2008-2013, consistent with some existing studies [29, 30].

(3) After the implementation of the new health reform, both outpatients and inpatients began to pay more attention to service quality and medical expense. Specifically, although the overall satisfaction of patients largely improved, the proportion of patients who were most dissatisfied with "low medical service level," "poor service attitude," and "high medical costs" of the total unsatisfied population significantly increased from in 2008-2013. 
(4) The trust relationship between patients and doctors largely improved in 2008-2013 because of the new health reform. This finding filled the gap left by existing studies to some extent. However, this conclusion seems to contradict the result indicating a marked increase in both "low medical service level" and "poor service attitude" in terms of being the most dissatisfying items. Nevertheless, note that a significant decreasing trend was identified in the unsatisfactory proportion during these 10 years, especially in the period of 2008-2013. This outcome indicates that, although issues relevant to the medical capability of doctors attracted the attention of patients, the overall patient-physician relationship largely improved.

(5) By comparing the patients in the urban and rural areas, we found that the increase in patient satisfaction of the latter was more considerable. For example, the unsatisfactory proportion of outpatients and inpatients in the urban areas decreased by $37.45 \%$ and $48.26 \%$, respectively, in $2003-$ 2013 , and that in the rural areas decreased by $47.73 \%$ and $49.26 \%$, respectively, during the same period of time. This difference was mainly caused by the change in the new health reform that the rural areas should be given the most importance [31].

\subsection{Interpretation of findings}

With the development of the economy, the quality of hardware devices, such as medical equipment, can be directly and easily improved in a short period of time. By contrast, how to enhance the medical ability and professional quality of physicians, especially of those in primary hospitals [32,33], and how to optimize the allocation of medical resources from a national perspective remain great challenges for the government. These problems can be viewed as the main cause of the phenomena of "difficulty and high cost of getting medical service" in China to date, and they are continuously cited as the primary solution targets by healthcare policies [34]. Therefore, sustainable and multi-sided modifications need to be considered by the Chinese government from the current status and long-term planning perspective.

According to Yan et al. [35], the healthcare system in China has faced a financial crisis in recent years, and this crisis is caused by the considerable gap between the growth rate of healthcare expenditure and that of the incomes of healthcare funds and budgets. To control the excessive growth of healthcare expenditure, the Chinese government has carried out a series of cost control actions or policies since 2012. However, based on our findings, the performance of these actions is relatively low. This conclusion is consistent with that of Ref. [35], who found that most of the cost control actions implemented by hospitals are lowering the quality of healthcare, leading to patient satisfaction not being considered as 
high priority. Moreover, Pan et al. found that the expensive medical charges were mainly responsible for patient dissatisfaction [36].

Previous studies also found a significant relationship between the hospital referral mechanism and patient satisfaction [33]. A rational referral mechanism is the basis for scientifically controlling and optimizing the allocation of medical resources and the mobility of patients. In 2009, China launched a two-way transfer mechanism in the new health reform. This referral mode is not mandatory but a voluntary selection behavior for the patients themselves. The only constraint measure carried out by the Chinese government is to implement the health insurance policy that provides the highest reimbursement rate for patients who comply with this mode. However, the fact is that the performance of this transfer mechanism is relatively weak. Zhang et al. stated that the "transferring service at the primary hospitals" and the "admission service at the higher-level hospitals" are the two main factors causing patient dissatisfaction [38]. These two aspects can sum up the ineffectiveness in the policy implementation process, such as cumbersome and unreasonable procedures.

With respect to the patient-physician relationship, although it improved in $2008-2013$, only $21.3 \%$ of the outpatients and $19.07 \%$ of the inpatients reported that they complete trusted their doctors. Therefore, low public trust between patients and doctors remains a potential problem in China's healthcare system. To solve this problem, enhancing healthcare experiences, clearly defining patients' role in the treatment proposed by healthcare administrators [39], and improving the number and quality of family doctors in community health service centers [40] seem to be effective and practical measures.

To address the gap in medical quality between urban and rural areas, many previous studies found that compared with the healthcare institutions in the rural areas of China, those in the urban areas are equipped with more and better health resources, such as financial, human, and material resources [41]. As a result, the level of patient satisfaction and experience in China's public hospitals seemed to be higher in the urban than in the rural areas [42]. However, we found a relatively contrasting phenomenon. The satisfaction degree of both outpatients and inpatients in the rural areas was confirmed to be higher in urban areas in these 10 years. The main reason for this difference is the different datasets used. However, because of the use of national population-based survey data, our conclusion seems to be more convincing. Since the promulgation of the New Rural Cooperative Medical Scheme (NCMS) in 2009 to improve the health of rural residents, the satisfaction of patients in the rural areas in China has largely increased, especially that of the poor ones [43]. Specifically, the NCMS has substantially advanced healthcare access and application and effectively reduced the medical impoverishment of low-income rural regions. However, this program has failed to decrease the financial burden of outpatient medical 
costs of poor communities [43], and this issue should be considered by the government in further modifications and reformations.

\subsection{Policy implications}

These findings have two policy implications. First, our findings can be interpreted as the basis for improvement to further advance the healthcare reform in China. More effective strategies need to be conducted to reduce the medical costs and optimize the visiting mechanism for patients, especially for outpatients. Moreover, how to provide a more balanced medical resource allocation should be considered by policymakers to decrease the occurrence of the serious crowding phenomenon in tertiary hospitals. Note that unlike the rapid improvement in hardware devices, the boost in the allocation of medical resources seems to be much difficult in China, the country with the largest population and the thirdlargest land area in the world. Therefore, long-term, sustainable, and multi-sided modifications need to be considered by the Chinese government.

Second, the results raise the concern about the rebuilding of the patient-physician trust relationship. Under the perception that medical services can be viewed as credence goods, enhancing the trust between patients and physicians is considered to be the only effective way to reduce the risk of insufficient and unnecessary medical services, excessive medical charges, and medical workplace violence. To achieve this goal, the establishment of a rational referral mechanism and a comprehensive family doctor system as well as the improvement of the overall performance of primary healthcare providers should be given attention in further political focuses.

\section{Limitations}

This study is primarily limited by the unavailability of patient satisfaction-related data from the NHSS. First, some environmental and individual factors related to patient satisfaction, such as organizational features [44], and doctor-related factors [45], cannot be found in the NHSS. The addition of such queries to future rounds of the NHSS questionnaire would be valuable. Second, the changes across the three rounds of NHSS surveys related to patient satisfaction measures restrict the policy value of the NHSS data. For example, data on the patient-physician trust relationship are only included in the fourth (2008) and fifth (2013) round of surveys because of unknown reasons. Thus, only the subgroup trend and comparison analyses were conducted in the present paper.

\section{Conclusions}

Between 2003 and 2013, patient satisfaction was largely improved in China, indicating that the direction of the new health reform implemented in 2009 is correct to a large extent. During these 10 years, some traditional problems, such as the quality of medical equipment and medical treatment environment, were effectively solved. However, how to comprehensively improve patient satisfaction remains a challenging 
national public health problem in China, as nearly one-fourth of the outpatients and approximately onethird of the inpatients were dissatisfied with the Chinese health system in 2013. More national actions focusing on the optimization of the visiting mechanism, the deduction of medical costs, and the improvement of doctors' service and medical quality should be considered by the Chinese government in further healthcare policies to reach or exceed the general expectation of patients.

\section{Declarations}

\section{Declaration of interest}

The authors declare no conflict of interest.

\section{Ethical considerations}

This study was performed in accordance with the ethical guidelines from the Ethics Committee of Beijing Jiaotong University. All subjects gave their written informed consent in accordance with the Declaration of Helsinki. The protocol was approved by the Ethics Committee of Beijing Jiaotong University.

\section{Acknowledgement}

This research was supported by grants from the National Social Science Fund of China under Grant No.18ZDA086.

\section{References}

[1] Williams B. Patient satisfaction: a valid concept? Soc. Sci. Med. 1994; 38(4): 509-516. doi: 10.1016/0277-9536(94)90247-X

[2] Sitzia J, Wood N. Patient satisfaction: a review of issues and concepts. Soc. Sci. Med. 1997; 45(12): 1829-1843. doi: 10.1016/S0277-9536(97)00128-7

[3] Ruggieri TG, Berta P, Murante AM, Nuti S. Patient satisfaction, patients leaving hospital against medical advice and mortality in Italian university hospitals: a cross-sectional analysis. BMC Health Serv. Res. 2018; 18(1): 51. doi: 10.1186/s12913-018-2846-y

[4] Wang YC, Ganzorig B, Wu CC, Iqbal U, Khan HAA, Hsieh WS., et al. Patient satisfaction with dermatology teleconsultation by using MedX. Comput. Meth. Programs Biomed. 2018; 167: 37-42. doi: 10.1016/j.cmpb.2018.10.015 
[5] Chen K, Chiou CF, Plauschinat CA, Frech F, Harper A, Dubois R. Patient satisfaction with antihypertensive therapy. J. Hum. Hypertens. 2005; 19(10):793-799. doi: 10.1038/sj.jhh.1001899

[6] Zimmerman M, Mehring LB, Moon S, Holst CG. Measuring psychiatric patients satisfaction with the initial evaluation: a comparison of 2 measures. Psychiatry Res. 2019; 273: 509-513. doi:

10.1016/j.psychres.2019.01.072

[7] Graham B. Defining and measuring patient satisfaction. J. Hand Surg. 2016; 41(9): 929-931. doi: 10.1016/j.jhsa.2016.07.109

[8] Tang L. The influences of patient's trust in medical service and attitude towards health policy on patient's overall satisfaction with medical service and sub satisfaction in China. BMC Public Health 2011; 11: 472. doi: 10.1186/1471-2458-11-472

[9] Howden C, Pressey AD. Customer value creation in professional service relationships: the case of credence goods. Serv. Ind. J. 2008; 28(6): 789-812. doi: 10.1080/02642060801990361

[10] Che YK. Customer return policies for experience goods. J. Indust. Econ. 1996; 44(1):17-24. doi: $10.2307 / 2950557$

[11] Wan $Y$, Nakayama $M$, Sutcliffe $N$. The impact of age and shopping experiences on the classification of search, experience, and credence goods in online shopping. Inf. Syst. E-Bus. Manag. 2012; 10(1): 135-148. doi: 10.1007/s10257-010-0156-y

[12] Cai W, Deng L, Liu M, Yu M. Antecedents of medical workplace violence in South China. J. Interpers. Violence 2011; 26(2):312-327. doi: 10.1177/0886260510362885

[13] Yan Z, Wan D, Li L. Patient satisfaction in two Chinese provinces: rural and urban differences. Int. J. Qual. Health Care 2011; 23(4): 384-389. doi: 10.1093/intqhc/mzr034

[14] Jie W, Xin-Liang W, Hao-Bin Y, Tu-Bao Y, Lamberto M. Development of an in-patient satisfaction questionnaire for the Chinese population. PloS One 2015; 10(12): e0144785. doi: 10.1371/journal.pone. 0144785

[15] Shan L, Ye L, Ding D, Wu Q, Liu C, Jiao M., et al. Patient satisfaction with hospital inpatient care: effects of trust, medical insurance and perceived quality of care. PloS One 2016; 11(10): e0164366. doi: 10.1371/journal.pone.0164366

[16] Jiang F, Rakofsky J, Zhou H, Hu L, Tang YL. Satisfaction of psychiatric inpatients in China: clinical and institutional correlates in a national sample. BMC Psychiatry 2019; 19(1): 19. doi: 10.1186/s12888019-2011-0

[17] Wang H, Gusmano MK, Cao Q. An evaluation of the policy on community health organizations in China: will the priority of new healthcare reform in china be a success? Health Policy 2011; 99(1): 37-43. 
doi: 10.1016/j.healthpol.2010.07.003

[18] Yan Z, Wan D, Li L. Patient satisfaction in two Chinese provinces: rural and urban differences. Int. J. Qual. Health Care 2011; 23(4): 384-389. doi: 10.1093/intqhc/mzr034

[19] Wang X, Jiang R, Li J, Chen J, Burström B, Burström K. What do patients care most about in China's public hospitals? interviews with patients in Jiangsu province. BMC Health Serv. Res. 2018; 18(1): 97. doi: $10.1186 / \mathrm{s} 12913-018-2903-6$

[20] Shen Q, Tang L. Patient Preferences, Concerns, and Satisfaction with Providers before the Chinese Urban Health System Reform: A Social Groups Analysis. Working paper, Asia-Pacific Research Center, Stanford University, 2010;

[21] Eggleston K, Lindelow M, Ling L, Qingyue $M$, Wagstaff A. Health service delivery in China: a literature review. Health Econ. 2010; 17(2): 149-165. doi: 10.1002/hec.1306

[21] Tucker JD, Cheng Y, Wong B, Gong N, Nie J. B, Zhu W., et al. Patient-physician mistrust and violence against physicians in Guangdong province, China: a qualitative study. BMJ Open 2015; 5(10): e008221. doi: 10.1136/bmjopen-2015-008221

[22] Tucker JD, Wong B, Nie J. B, Kleinman A. Rebuilding patient-physician trust in China. The Lancet 2016; 388(10046): 755. doi: 10.1016/S0140-6736(16)31362-9

[23] Center for Health Statistics and Information of the National Health and Family Planning Commission of the People's Republic of China. An Analysis Report of National Health Services Survey. Peking Union Medical College Press, Beijing, 2016.

[24] Ning P, Cai M, Cheng P, Zhang Y, Schwebel DC, Yang Y., et al. Trends in injury morbidity in China, 1993-2013: a longitudinal analysis of population-based survey data. Accid. Anal. Prev. 2018; 113: 179186.

[25] Andrade CC, Lima ML, Pereira CR, Fornara F, Bonaiuto M. Inpatients' and outpatients' satisfaction: the mediating role of perceived quality of physical and social environment. Health Place 2013; $21: 122-132$. doi: 10.1016/j.healthplace.2013.01.013

[26] Fornara F, Bonaiuto M, Bonnes M. Perceived hospital environment quality indicators: a study of orthopaedic units. J. Environ. Psychol. 2006; 26: 321-334. doi: 10.1016/j.jenvp.2006.07.003

[27] Mathews B, Bromfield L, Walsh K, Cheng Q, Norman RE. Reports of child sexual abuse of boys and girls: longitudinal trends over a 20-year period in Victoria, Australia. Child Abuse Negl. 2017; 66: 9-22. doi: 10.1016/j.chiabu.2017.01.025

[28]You L, Aiken LH, Sloane DM, Liu K, Hu Y, Jiang X., et al. Hospital nursing, care quality, and patient satisfaction: cross-sectional surveys of nurses and patients in hospitals in China and Europe. Int. J. Nurs. 
Stud. 2013; 50(2): 154-161. doi: 10.1016/j.jjnurstu.2012.05.003

[29] Tao L, Liu J. Understanding self-organized regularities in healthcare services based on autonomy oriented modeling. Nat. Comput. 2015; 14(1): 7-24. doi: 10.1007/s11047-014-9472-3

[30] Sun J, Lin Q, Zhao P, Zhang Q, Xu K, Chen H, et al. Reducing waiting time and raising outpatient satisfaction in a Chinese public tertiary general hospital-an interrupted time series study.

BMC Public Health 2017; 17(1): 668. doi: 10.1186/s12889-017-4667-z

[31] Flatø $\mathrm{H}$, Zhang $\mathrm{H}$. Inequity in level of healthcare utilization before and after universal health coverage reforms in China: evidence from household surveys in Sichuan province. Int. J. Equity Health 2016; 15(1):96. doi: 10.1186/s12939-016-0385-x

[32] Li J, Wang P, Kong X, Liang H, Zhang X, Shi L. Patient satisfaction between primary care providers and hospitals: a cross-sectional survey in Jilin province, China. Int. J. Qual. Health Care 2016; 28(3): 346354.doi: 10.1093/intqhc/mzw038

[33] Zhang X, Wang T, Yu Y, Zhao S. Key nodes affecting patient satisfaction in a cross-regional referral service process: an empirical analysis study in Sichuan. BMC Health Serv. Res. 2018; 18(1): 840. doi: $10.1186 /$ s12913-018-3460-8

[34] Yang Q, Dong H. A response to the commentary entitled: "addressing the shortage of health professionals in rural China: issues and progress". Int. J. Qual. Health Care 2015; 4(5): 329-330. doi: 10.15171/ijhpm.2015.83

[35] Yan J, Lin HH, Zhao D, Hu Y, Shao R. China's new policy for healthcare cost-control based on global budget: a survey of 110 clinicians in hospitals. BMC Health Serv. Res. 2019; 19(1): 84. doi: $10.1186 /$ s12913-019-3921-8

[36] Pan J, Liu D, Ali S. Patient dissatisfaction in China: what matters. Soc. Sci. Med. 2015; 143: 145153. doi: 10.1016/j.aap.2018.01.017

[39] Ye BZ, Wang XZ, Wang F, Zhang P, Cheng Y., et al. Patients' sense of responsibility to healthcare providers and its predictors: A national cross-sectional survey in China. PloS One 2019; 13 (12): e0207361. doi: 10.1371/journal.pone.0207361

[40] Huang JL, Liu SS, He RR, Fang S, Lu W, et al. Factors associated with residents' contract behavior with family doctors in community health service centers: A longitudinal survey from China. PloS One, 2018; 13 (11):e0208200. doi: 10.1371/journal.pone.0208200

[41] Sun XX, Meng HD, Ye ZQ, Conner, KO, Duan ZQ, Liu DP. Factors associated with the choice of primary care facilities for initial treatment among rural and urban residents in Southwestern China. PloS One 2019; 14(2): e0211984. doi: 10.1371/journal.pone.0211984 
[42] Wang X, Chen J, Burström B, Burström K. Exploring pathways to outpatients' satisfaction with health care in Chinese public hospitals in urban and rural areas using patient-reported experiences. Int. J. Equity Health 2019; 18(1): 29. doi:10.1186/s12939-019-0932-3

[43] Gu DX, Yang XJ, Li XG, Lian CY, Zhong JH. Innovating new rural cooperative medical scheme (NCMS) for better patient satisfaction in rural China. Int. J. Environ. Res. Public Health 2018; 15(9): 2007. doi: 10.3390/ijerph15092007

[44] Mattarozzi K, Baldin E, Zenesini C, Solari A, Amato MP, Leone M., et al. Effect of organizational features on patient satisfaction with care in Italian multiple sclerosis centres. Eur. J. Neurol. 2017; 24(4): 631-637. doi: 10.1111/ene.13263

[45] Linn L. S, Brook RH, Clark VA, Davies AR, Fink A, Kosecoff J. Physician and patient satisfaction as factors related to the organization of internal medicine group practices. Med. Care 1985; 23(10): 11711178. doi: 10.1097/00005650-198510000-00006

\section{Tables}

Table 1 Items and their available survey years of NHSS included in the hospital satisfaction assessment and the most dissatisfying items of outpatients and inpatients 


\begin{tabular}{|c|c|c|c|}
\hline Group & Measures & Items & $\begin{array}{l}\text { Available survey } \\
\text { years }\end{array}$ \\
\hline \multirow[t]{16}{*}{ Outpatients } & Unsatisfactory rate & & 2003, 2008, 2013 \\
\hline & \multirow{5}{*}{$\begin{array}{l}\text { Hospital satisfaction } \\
\text { assessment }\end{array}$} & Waiting time for treatment & 2003, 2008, 2013 \\
\hline & & Interpretation clarity of treatment & 2003, 2008, 2013 \\
\hline & & Listing the seriousness of patients' illness & 2003, 2008, 2013 \\
\hline & & $\begin{array}{l}\text { Evaluation of the medical treatment } \\
\text { environment }\end{array}$ & $2003,2008,2013$ \\
\hline & & Trust degree in the doctor & 2008,2013 \\
\hline & \multirow[t]{10}{*}{ Most dissatisfied items } & High medical costs & 2003, 2008, 2013 \\
\hline & & Poor medical equipment & $2003,2008,2013$ \\
\hline & & Low medical service level & 2003, 2008, 2013 \\
\hline & & Poor service attitude & 2003, 2008, 2013 \\
\hline & & Cumbersome procedures & 2003, 2008, 2013 \\
\hline & & Unreasonable charges & 2008, 2013 \\
\hline & & Long waiting time for treatment & 2008, 2013 \\
\hline & & Unnecessary services & 2008, 2013 \\
\hline & & Fewer drug varieties & 2008, 2013 \\
\hline & & Others & $2003,2008,2013$ \\
\hline \multirow[t]{17}{*}{ Inpatients } & Unsatisfactory rate & & 2003, 2008, 2013 \\
\hline & \multirow{6}{*}{$\begin{array}{l}\text { Hospital satisfaction } \\
\text { assessment }\end{array}$} & Interpretation clarity of treatment & 2003, 2008, 2013 \\
\hline & & Listing the seriousness of patients' illness & 2003, 2008, 2013 \\
\hline & & $\begin{array}{l}\text { Evaluation of the medical treatment } \\
\text { environment }\end{array}$ & $2003,2008,2013$ \\
\hline & & Convenience of querying medical costs & 2003, 2008 \\
\hline & & Convenience of complaint & 2003, 2008 \\
\hline & & Trust degree in the doctor & 2008, 2013 \\
\hline & \multirow[t]{10}{*}{ Most dissatisfying items } & High medical costs & 2003, 2008, 2013 \\
\hline & & Poor medical equipment & 2003, 2008, 2013 \\
\hline & & Low medical service level & 2003, 2008, 2013 \\
\hline & & Poor service attitude & 2003, 2008, 2013 \\
\hline & & Cumbersome procedures & 2003, 2008, 2013 \\
\hline & & Unreasonable charges & 2008,2013 \\
\hline & & Long waiting time for treatment & 2008, 2013 \\
\hline & & Unnecessary services & 2008, 2013 \\
\hline & & Fewer drug varieties & 2008,2013 \\
\hline & & Others & 2003, 2008, 2013 \\
\hline
\end{tabular}


Table 2 Number of outpatients and inpatients in the urban and rural areas in China according to the NHSS in 2003, 2008, and 2013

\begin{tabular}{|l|l|l|l|l|l|l|l|}
\hline \multirow{2}{*}{ Location } & & \multicolumn{3}{|l}{2003} & \multicolumn{2}{l|}{2008} & \multicolumn{2}{l|}{2013} \\
\hline \multirow{4}{*}{ Urban } & & $\mathrm{n}$ & $\%$ & $\mathrm{n}$ & $\%$ & $\mathrm{n}$ & $\%$ \\
\cline { 2 - 8 } & Outpatients & 3,244 & 64.4 & 3,104 & 54.5 & 12,243 & 50.3 \\
\cline { 2 - 8 } & Inpatients & 1,795 & 35.6 & 2,591 & 45.5 & 12,110 & 49.7 \\
\cline { 2 - 8 } & Total & 5,039 & 100 & 5,695 & 100 & 24,353 & 100 \\
\hline \multirow{5}{*}{ Rural } & Outpatients & 10,766 & 71.8 & 9,972 & 57.9 & 12,357 & 49.5 \\
\cline { 2 - 8 } & Inpatients & 4,219 & 28.2 & 7,243 & 42.1 & 12,630 & 50.5 \\
\cline { 2 - 8 } & Total & 14,985 & 100 & 17,215 & 100 & 24,987 & 100 \\
\hline
\end{tabular}

Table 3 Hospital satisfaction assessment results of the outpatients in China, 2003-2013 


\begin{tabular}{|c|c|c|c|c|c|}
\hline & & & 2003-2008 & 2008-2013 & 2003-2013 \\
\hline Measures & Level $^{\#}$ & Location & $\begin{array}{c}\text { Change } \\
(\%)\end{array}$ & $\begin{array}{c}\text { Change } \\
(\%)\end{array}$ & $\begin{array}{c}\text { Change } \\
(\%)\end{array}$ \\
\hline \multirow[t]{9}{*}{ Waiting time for treatment } & \multirow[t]{3}{*}{ I } & Total & -11.42 & 6.95 & -5.27 \\
\hline & & Urban & -13.26 & 21.15 & 5.09 \\
\hline & & Rural & -10.83 & 11.44 & -0.62 \\
\hline & \multirow[t]{3}{*}{ II } & Total & 17.52 & -10.48 & 5.20 \\
\hline & & Urban & 5.41 & -9.61 & -4.72 \\
\hline & & Rural & 22.37 & -20.46 & -2.66 \\
\hline & \multirow[t]{3}{*}{ III } & Total & 44.35 & -5.78 & 36.01 \\
\hline & & Urban & 40.06 & -35.16 & -9.19 \\
\hline & & Rural & 46.11 & -13.06 & 27.03 \\
\hline \multicolumn{2}{|l|}{$X^{2}$} & \multirow[t]{2}{*}{ Total } & 179.038 & 57.832 & 79.245 \\
\hline \multicolumn{2}{|l|}{$P$ value } & & 0.000 & 0.000 & 0.000 \\
\hline \multicolumn{2}{|l|}{$X^{2}$} & \multirow[t]{2}{*}{ Urban } & 43.182 & 125.072 & 8.251 \\
\hline \multicolumn{2}{|l|}{$P$ value } & & 0.000 & 0.000 & 0.016 \\
\hline \multicolumn{2}{|l|}{$X^{2}$} & \multirow[t]{2}{*}{ Rural } & 140.056 & 128.01 & 16.162 \\
\hline \multicolumn{2}{|l|}{$P$ value } & & 0.000 & 0.000 & 0.000 \\
\hline \multirow[t]{9}{*}{ Interpretation clarity of the treatment } & \multirow[t]{3}{*}{ I } & Total & -1.45 & 33.43 & 31.50 \\
\hline & & Urban & 0.50 & 23.94 & 24.55 \\
\hline & & Rural & -2.11 & 38.45 & 35.53 \\
\hline & \multirow[t]{3}{*}{ II } & Total & 5.85 & -44.32 & -41.06 \\
\hline & & Urban & -2.19 & -32.52 & -34.00 \\
\hline & & Rural & 8.25 & -49.70 & -45.55 \\
\hline & \multirow[t]{3}{*}{ III } & Total & -32.54 & -76.19 & -83.94 \\
\hline & & Urban & -4.38 & -76.18 & -77.23 \\
\hline & & Rural & -40.65 & -82.40 & -89.55 \\
\hline \multicolumn{2}{|l|}{$X^{2}$} & Total & 54.959 & 1696.906 & 1890.272 \\
\hline \multicolumn{2}{|l|}{$P$ value } & & 0.000 & 0.000 & 0.000 \\
\hline \multicolumn{2}{|l|}{$X^{2}$} & Urban & 0.37 & 372.9 & 418.767 \\
\hline \multicolumn{2}{|l|}{$P$ value } & & 0.831 & 0.000 & 0.000 \\
\hline \multicolumn{2}{|l|}{$X^{2}$} & Rural & 72.536 & 1335.417 & 1411.451 \\
\hline \multicolumn{2}{|l|}{$P$ value } & & 0.000 & 0.000 & 0.000 \\
\hline \multirow[t]{2}{*}{ Listing the seriousness of patients' illness } & \multirow[t]{2}{*}{$\mathrm{I}$} & Total & -1.47 & 46.55 & 44.40 \\
\hline & & & & & \\
\hline
\end{tabular}




\begin{tabular}{|c|c|c|c|c|c|}
\hline & & Urban & 5.14 & 36.73 & 43.76 \\
\hline & & Rural & -3.47 & 51.54 & 46.28 \\
\hline & \multirow[t]{3}{*}{ II } & Total & 6.48 & -52.93 & -49.89 \\
\hline & & Urban & -5.47 & -43.63 & -46.71 \\
\hline & & Rural & 10.21 & -57.42 & -53.07 \\
\hline & \multirow[t]{3}{*}{ III } & Total & -35.05 & -87.40 & -91.82 \\
\hline & & Urban & -25.52 & -86.32 & -89.81 \\
\hline & & Rural & -38.41 & -91.17 & -94.56 \\
\hline \multicolumn{2}{|l|}{$X^{2}$} & \multirow{2}{*}{ Total } & 86.473 & 2955.766 & 3336.655 \\
\hline \multicolumn{2}{|l|}{$\mathrm{P}$ value } & & 0.000 & 0.000 & 0.000 \\
\hline \multicolumn{2}{|l|}{$X^{2}$} & \multirow[t]{2}{*}{ Urban } & 13.668 & 771.529 & 1118.565 \\
\hline \multicolumn{2}{|l|}{$\mathrm{P}$ value } & & 0.001 & 0.000 & 0.000 \\
\hline \multicolumn{2}{|l|}{$X^{2}$} & \multirow[t]{2}{*}{ Rural } & 91.401 & 2107.995 & 2148.973 \\
\hline \multicolumn{2}{|l|}{$\mathrm{P}$ value } & & 0.000 & 0.000 & 0.000 \\
\hline \multirow{9}{*}{$\begin{array}{c}\text { Evaluation of the medical treatment } \\
\text { environment }\end{array}$} & \multirow[t]{3}{*}{ I } & Total & 7.61 & 46.25 & 70.73 \\
\hline & & Urban & 12.66 & 3.62 & 57.39 \\
\hline & & Rural & 4.99 & 70.73 & 16.73 \\
\hline & \multirow[t]{3}{*}{ II } & Total & -9.01 & -29.09 & -38.40 \\
\hline & & Urban & -15.14 & 0.45 & -35.48 \\
\hline & & Rural & -7.38 & -38.40 & -14.75 \\
\hline & \multirow[t]{3}{*}{ III } & Total & 10.85 & -83.55 & -88.94 \\
\hline & & Urban & -25.15 & -54.28 & -81.77 \\
\hline & & Rural & 17.78 & -88.94 & -65.78 \\
\hline \multicolumn{2}{|l|}{$X^{2}$} & \multirow{2}{*}{ Total } & 50.249 & 2056.236 & 2054.769 \\
\hline \multicolumn{2}{|l|}{$\mathrm{P}$ value } & & 0.000 & 0.000 & 0.000 \\
\hline \multicolumn{2}{|l|}{$X^{2}$} & \multirow[t]{2}{*}{ Urban } & 34.312 & 45.412 & 164.069 \\
\hline \multicolumn{2}{|l|}{$\mathrm{P}$ value } & & 0.000 & 0.000 & 0.000 \\
\hline \multicolumn{2}{|l|}{$X^{2}$} & \multirow[t]{2}{*}{ Rural } & 31.979 & 2088.868 & 2336.323 \\
\hline \multicolumn{2}{|l|}{$\mathrm{P}$ value } & & 0.000 & 0.000 & 0.000 \\
\hline \multirow[t]{6}{*}{ Trust degree in the doctor } & \multirow[t]{3}{*}{$\mathrm{I}^{\prime}$} & Total & 1 & 145.21 & 1 \\
\hline & & Urban & 1 & 58.26 & 1 \\
\hline & & Rural & 1 & 208.71 & 1 \\
\hline & \multirow[t]{3}{*}{ II' } & Total & 1 & -8.78 & 1 \\
\hline & & Urban & 1 & -5.19 & 1 \\
\hline & & & & & \\
\hline
\end{tabular}




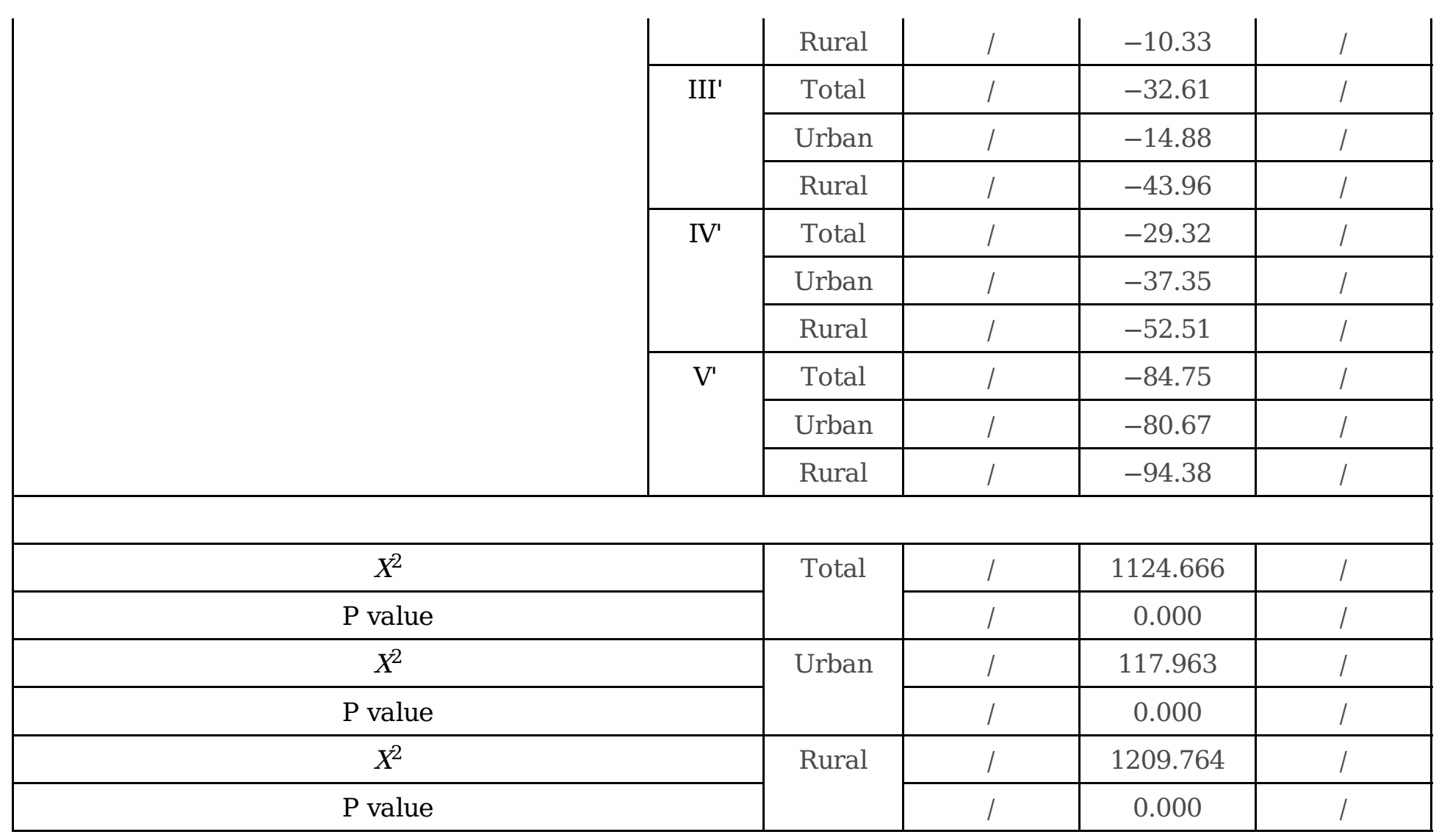

Note: \# I, II, and III measures "Very good/Good", "Normal", and "Very bad/Bad", respectively, and I', II', III', IV', and V' measures "Trust very much", "Trust", "Normal", "Distrust", and "Distrust very much", respectively.

Table 4 Most dissatisfying item results of the outpatients in China, 2003-2013 


\begin{tabular}{|c|c|c|c|c|}
\hline & & 2003-2008 & 2008-2013 & 2003-2013 \\
\hline Measures & Location & Change (\%) & Change (\%) & Change (\%) \\
\hline \multirow[t]{3}{*}{ High medical costs } & Total & -60.47 & 103.30 & -19.63 \\
\hline & Urban & -58.90 & 54.87 & -36.35 \\
\hline & Rural & -60.40 & 130.07 & -8.89 \\
\hline \multirow[t]{3}{*}{ Poor medical equipment } & Total & 52.22 & -94.89 & -92.22 \\
\hline & Urban & 73.28 & -93.93 & -89.48 \\
\hline & Rural & 44.73 & -92.21 & -88.72 \\
\hline \multirow[t]{3}{*}{ Low medical service level } & Total & -0.01 & 80.75 & 80.73 \\
\hline & Urban & 10.03 & 149.48 & 174.50 \\
\hline & Rural & -4.02 & 60.61 & 54.15 \\
\hline \multirow[t]{3}{*}{ Poor service attitude } & Total & 34.91 & 249.83 & 371.95 \\
\hline & Urban & 42.62 & 163.21 & 275.38 \\
\hline & Rural & 34.75 & 262.67 & 388.69 \\
\hline \multirow[t]{3}{*}{ Cumbersome procedures } & Total & 66.86 & -42.57 & -4.17 \\
\hline & Urban & 69.10 & -43.50 & -4.46 \\
\hline & Rural & 68.74 & -60.52 & -33.39 \\
\hline \multirow[t]{3}{*}{ Unreasonable charges } & Total & l & 37.00 & l \\
\hline & Urban & l & -20.11 & l \\
\hline & Rural & I & 106.03 & l \\
\hline \multirow[t]{3}{*}{ Long waiting time for treatment } & Total & I & -9.08 & l \\
\hline & Urban & l & -49.89 & l \\
\hline & Rural & I & -14.79 & l \\
\hline \multirow[t]{3}{*}{ Unnecessary Services } & Total & l & -2.82 & l \\
\hline & Urban & I & -40.08 & l \\
\hline & Rural & l & -19.98 & l \\
\hline \multirow[t]{3}{*}{ Fewer drug varieties } & Total & l & -73.26 & l \\
\hline & Urban & l & -77.14 & 1 \\
\hline & Rural & l & -57.20 & I \\
\hline \multirow[t]{3}{*}{ Others } & Total & -63.66 & -12.74 & -68.29 \\
\hline & Urban & -60.87 & -18.28 & -68.02 \\
\hline & Rural & -64.60 & -8.83 & -67.72 \\
\hline$X^{2}$ & \multirow[t]{2}{*}{ Total } & 3348.595 & 9453.02 & 23051.73 \\
\hline$P$ value & & 0.000 & 0.000 & 0.000 \\
\hline$X^{2}$ & \multirow[t]{2}{*}{ Urban } & 2303.79 & 2115.737 & 12474.1 \\
\hline $\mathrm{P}$ value & & 0.000 & 0.000 & 0.000 \\
\hline$X^{2}$ & Rural & 2439.33 & 6056.121 & 11964.5 \\
\hline
\end{tabular}




\begin{tabular}{|l|l|l|l|l|} 
P value & & 0.000 & 0.000 & 0.000 \\
\hline
\end{tabular}

Table 5 Hospital satisfaction assessment results of the inpatients in China, 2003-2013 


\begin{tabular}{|c|c|c|c|c|c|}
\hline & & & $2003-2008$ & $2008-2013$ & $2003-2013$ \\
\hline Measures & Level $^{\#}$ & Location & $\begin{array}{c}\text { Change } \\
(\%)\end{array}$ & $\begin{array}{c}\text { Change } \\
(\%)\end{array}$ & $\begin{array}{c}\text { Change } \\
(\%)\end{array}$ \\
\hline \multirow[t]{9}{*}{ Interpretation clarity of the treatment } & \multirow[t]{3}{*}{$\mathrm{I}$} & Total & 2.34 & 10.95 & 13.55 \\
\hline & & Urban & 5.87 & 2.66 & 8.70 \\
\hline & & Rural & 1.11 & 16.48 & 17.78 \\
\hline & \multirow[t]{3}{*}{ II } & Total & 2.10 & -26.95 & -25.42 \\
\hline & & Urban & -7.18 & -6.54 & -13.25 \\
\hline & & Rural & 4.93 & -37.82 & -34.75 \\
\hline & \multirow[t]{3}{*}{ III } & Total & -56.31 & -17.88 & -64.13 \\
\hline & & Urban & -50.11 & -13.73 & -56.96 \\
\hline & & Rural & -58.57 & -39.55 & -74.96 \\
\hline \multicolumn{2}{|l|}{$X^{2}$} & \multirow[t]{2}{*}{ Total } & 80.066 & 230.012 & 334.706 \\
\hline \multicolumn{2}{|l|}{$P$ value } & & 0.000 & 0.000 & 0.000 \\
\hline \multicolumn{2}{|l|}{$X^{2}$} & \multirow[t]{2}{*}{ Urban } & 22.008 & 4.475 & 64.097 \\
\hline \multicolumn{2}{|l|}{$P$ value } & & 0.000 & 0.107 & 0.000 \\
\hline \multicolumn{2}{|l|}{$X^{2}$} & \multirow[t]{2}{*}{ Rural } & 60.339 & 338.703 & 363.738 \\
\hline$P$ value & & & 0.000 & 0.000 & 0.000 \\
\hline \multirow[t]{9}{*}{ Listing the seriousness of patients' illness } & \multirow[t]{3}{*}{ I } & Total & 4.03 & 19.58 & 24.39 \\
\hline & & Urban & 7.65 & 11.59 & 20.13 \\
\hline & & Rural & 2.75 & 24.74 & 28.18 \\
\hline & \multirow[t]{3}{*}{ II } & Total & 1.03 & -37.52 & -36.87 \\
\hline & & Urban & -4.31 & -22.33 & -25.68 \\
\hline & & Rural & 2.37 & -45.98 & -44.70 \\
\hline & \multirow[t]{3}{*}{ III } & Total & -53.95 & -62.51 & -82.74 \\
\hline & & Urban & -53.87 & -57.72 & -80.49 \\
\hline & & Rural & -53.14 & -74.85 & -88.22 \\
\hline \multicolumn{2}{|l|}{$X^{2}$} & Total & 101.688 & 697.953 & 1023.024 \\
\hline \multicolumn{2}{|l|}{$\mathrm{P}$ value } & & 0.000 & 0.000 & 0.000 \\
\hline \multicolumn{2}{|l|}{$X^{2}$} & Urban & 38.224 & 99.442 & 324.768 \\
\hline \multicolumn{2}{|l|}{ P value } & & 0.000 & 0.000 & 0.000 \\
\hline \multicolumn{2}{|l|}{$X^{2}$} & Rural & 62.342 & 710.54 & 811.26 \\
\hline \multicolumn{2}{|l|}{$P$ value } & & 0.000 & 0.000 & 0.000 \\
\hline \multirow[t]{2}{*}{ Evaluation of the medical treatment } & \multirow[t]{2}{*}{ I } & Total & 2.49 & 17.03 & 19.94 \\
\hline & & & & & \\
\hline
\end{tabular}




\begin{tabular}{|c|c|c|c|c|c|}
\hline \multirow[t]{8}{*}{ environment } & & Urban & 9.28 & -1.77 & 7.35 \\
\hline & & Rural & 0.23 & 29.35 & 29.64 \\
\hline & \multirow[t]{3}{*}{ II } & Total & -4.64 & -18.34 & -22.12 \\
\hline & & Urban & -8.49 & 5.34 & -3.60 \\
\hline & & Rural & -4.08 & -30.62 & -33.45 \\
\hline & \multirow[t]{3}{*}{ III } & Total & 4.37 & -45.27 & -42.87 \\
\hline & & Urban & -36.50 & -11.72 & -43.95 \\
\hline & & Rural & 25.15 & -58.60 & -48.19 \\
\hline \multicolumn{2}{|l|}{$X^{2}$} & \multirow[t]{2}{*}{ Total } & 4.889 & 331.774 & 281.269 \\
\hline \multicolumn{2}{|l|}{$P$ value } & & 0.087 & 0.000 & 0.000 \\
\hline \multicolumn{2}{|l|}{$X^{2}$} & \multirow[t]{2}{*}{ Urban } & 20.056 & 3.736 & 38.901 \\
\hline \multicolumn{2}{|l|}{$P$ value } & & 0.000 & 0.154 & 0.000 \\
\hline \multicolumn{2}{|l|}{$X^{2}$} & \multirow[t]{2}{*}{ Rural } & 9.489 & 554.395 & 374.634 \\
\hline \multicolumn{2}{|l|}{$P$ value } & & 0.009 & 0.000 & 0.000 \\
\hline \multirow[t]{9}{*}{ Convenience of querying medical costs } & \multirow[t]{3}{*}{$\mathrm{I}$} & Total & 11.38 & 1 & 1 \\
\hline & & Urban & 8.36 & 1 & 1 \\
\hline & & Rural & 14.03 & 1 & 1 \\
\hline & \multirow[t]{3}{*}{ II } & Total & -4.88 & 1 & 1 \\
\hline & & Urban & -8.37 & 1 & 1 \\
\hline & & Rural & -5.18 & 1 & 1 \\
\hline & \multirow[t]{3}{*}{ III } & Total & -65.40 & 1 & 1 \\
\hline & & Urban & -58.77 & 1 & 1 \\
\hline & & Rural & -67.42 & 1 & 1 \\
\hline \multicolumn{2}{|l|}{$X^{2}$} & Total & 305.743 & 1 & 1 \\
\hline \multicolumn{2}{|l|}{$P$ value } & & 0.000 & 1 & 1 \\
\hline \multicolumn{2}{|l|}{$X^{2}$} & Urban & 47.461 & 1 & 1 \\
\hline \multicolumn{2}{|l|}{$P$ value } & & 0.000 & 1 & 1 \\
\hline \multicolumn{2}{|l|}{$X^{2}$} & Rural & 273.405 & 1 & 1 \\
\hline \multicolumn{2}{|l|}{$P$ value } & & 0.000 & 1 & 1 \\
\hline \multirow[t]{6}{*}{ Convenience of complaint } & \multirow[t]{3}{*}{ I } & Total & 26.99 & 1 & 1 \\
\hline & & Urban & 29.05 & 1 & 1 \\
\hline & & Rural & 27.22 & 1 & 1 \\
\hline & \multirow[t]{3}{*}{ II } & Total & -19.34 & 1 & 1 \\
\hline & & Urban & -29.46 & 1 & 1 \\
\hline & & & & & \\
\hline
\end{tabular}




\begin{tabular}{|c|c|c|c|c|c|}
\hline & & Rural & -16.15 & 1 & I \\
\hline & \multirow[t]{3}{*}{ III } & Total & -70.80 & 1 & I \\
\hline & & Urban & -75.96 & 1 & I \\
\hline & & Rural & -70.03 & l & I \\
\hline \multicolumn{2}{|l|}{$X^{2}$} & \multirow[t]{2}{*}{ Total } & 592.817 & 1 & I \\
\hline \multicolumn{2}{|l|}{$P$ value } & & 0.000 & 1 & I \\
\hline \multicolumn{2}{|l|}{$X^{2}$} & \multirow[t]{2}{*}{ Urban } & 189.645 & 1 & I \\
\hline \multicolumn{2}{|l|}{$\mathrm{P}$ value } & & 0.000 & 1 & I \\
\hline \multicolumn{2}{|l|}{$X^{2}$} & \multirow[t]{2}{*}{ Rural } & 430.998 & 1 & I \\
\hline $\mathrm{P}$ value & & & 0.000 & 1 & I \\
\hline \multirow[t]{15}{*}{ Trust degree in the doctor } & \multirow[t]{3}{*}{$\mathrm{I}^{\prime}$} & Total & 1 & 86.56 & I \\
\hline & & Urban & 1 & 23.41 & I \\
\hline & & Rural & 1 & 132.58 & I \\
\hline & \multirow[t]{3}{*}{$\mathrm{II}^{\prime}$} & Total & 1 & -10.42 & I \\
\hline & & Urban & 1 & -4.98 & I \\
\hline & & Rural & 1 & -11.00 & 1 \\
\hline & \multirow[t]{3}{*}{ III' } & Total & 1 & -7.86 & 1 \\
\hline & & Urban & 1 & 0.17 & 1 \\
\hline & & Rural & 1 & -20.39 & 1 \\
\hline & \multirow[t]{3}{*}{$\mathrm{IV}^{\prime}$} & Total & 1 & 37.12 & 1 \\
\hline & & Urban & 1 & 39.08 & 1 \\
\hline & & Rural & 1 & -3.53 & 1 \\
\hline & \multirow[t]{3}{*}{$\mathrm{V}^{\prime}$} & Total & 1 & -74.67 & 1 \\
\hline & & Urban & 1 & -76.36 & I \\
\hline & & Rural & 1 & -79.75 & I \\
\hline \multicolumn{2}{|l|}{$X^{2}$} & \multirow[t]{2}{*}{ Total } & 1 & 448.189 & I \\
\hline \multicolumn{2}{|l|}{$\mathrm{P}$ value } & & 1 & 0.000 & I \\
\hline \multicolumn{2}{|l|}{$X^{2}$} & \multirow[t]{2}{*}{ Urban } & 1 & 42.676 & 1 \\
\hline \multicolumn{2}{|l|}{$\mathrm{P}$ value } & & 1 & 0.000 & I \\
\hline \multicolumn{2}{|l|}{$X^{2}$} & \multirow[t]{2}{*}{ Rural } & 1 & 481.89 & 1 \\
\hline \multicolumn{2}{|l|}{$\mathrm{P}$ value } & & I & 0.000 & I \\
\hline
\end{tabular}

Note: \# I, II, and III measures "Very good/Good," "Normal," and "Very bad/Bad," respectively, and I', II', III', IV', and V' measures "Trust very much", "trust", "Normal", "Distrust", and "Distrust very much", respectively. 
Table 6 Most dissatisfying item results of the inpatients in China, 2003-2013

Page 28/31 


\begin{tabular}{|c|c|c|c|c|}
\hline & & 2003-2008 & 2008-2013 & 2003-2013 \\
\hline Measures & Location & Change (\%) & Change (\%) & Change (\%) \\
\hline \multirow[t]{3}{*}{ High medical costs } & Total & -3.18 & 29.41 & 25.29 \\
\hline & Urban & -5.84 & 20.31 & 13.29 \\
\hline & Rural & -1.32 & 26.13 & 24.46 \\
\hline \multirow[t]{3}{*}{ Poor medical equipment } & Total & 137.37 & -76.29 & -43.72 \\
\hline & Urban & 44.26 & -57.89 & -39.26 \\
\hline & Rural & 159.71 & -73.87 & -32.15 \\
\hline \multirow[t]{3}{*}{ Low medical service level } & Total & 136.40 & 187.76 & 580.28 \\
\hline & Urban & 84.65 & 201.26 & 456.28 \\
\hline & Rural & 161.06 & 215.92 & 724.74 \\
\hline \multirow[t]{3}{*}{ Poor service attitude } & Total & 106.71 & 132.30 & 380.19 \\
\hline & Urban & 83.13 & 103.25 & 272.22 \\
\hline & Rural & 120.23 & 168.96 & 492.33 \\
\hline \multirow[t]{3}{*}{ Cumbersome procedures } & Total & 656.40 & -87.69 & -6.92 \\
\hline & Urban & 751.27 & -86.93 & 11.26 \\
\hline & Rural & 624.88 & -86.34 & -1.01 \\
\hline \multirow[t]{3}{*}{ Unreasonable charges } & Total & I & -9.01 & I \\
\hline & Urban & l & -19.17 & l \\
\hline & Rural & I & -23.91 & I \\
\hline \multirow[t]{3}{*}{ Long waiting time for treatment } & Total & l & -77.51 & l \\
\hline & Urban & I & -79.43 & I \\
\hline & Rural & I & -87.64 & l \\
\hline \multirow[t]{3}{*}{ Unnecessary services } & Total & l & -2.72 & l \\
\hline & Urban & l & -35.55 & l \\
\hline & Rural & I & -8.15 & I \\
\hline \multirow[t]{3}{*}{ Fewer drug varieties } & Total & I & -47.08 & I \\
\hline & Urban & I & -17.24 & I \\
\hline & Rural & I & -34.95 & l \\
\hline \multirow[t]{3}{*}{ Others } & Total & -18.27 & -6.85 & -23.86 \\
\hline & Urban & -29.19 & -10.50 & -36.63 \\
\hline & Rural & -12.10 & -4.58 & -16.12 \\
\hline$X^{2}$ & \multirow[t]{2}{*}{ Total } & 615.26 & 4814.732 & 1076.711 \\
\hline$P$ value & & 0.000 & 0.000 & 0.000 \\
\hline$X^{2}$ & \multirow[t]{2}{*}{ Urban } & 138.125 & 1251.725 & 265.053 \\
\hline $\mathrm{P}$ value & & 0.000 & 0.000 & 0.000 \\
\hline$X^{2}$ & Rural & 464.678 & 3237.31 & 824.84 \\
\hline
\end{tabular}




\begin{tabular}{|l|l|l|l|l|} 
P value & & 0.000 & 0.000 & 0.000 \\
\hline
\end{tabular}

\section{Figures}

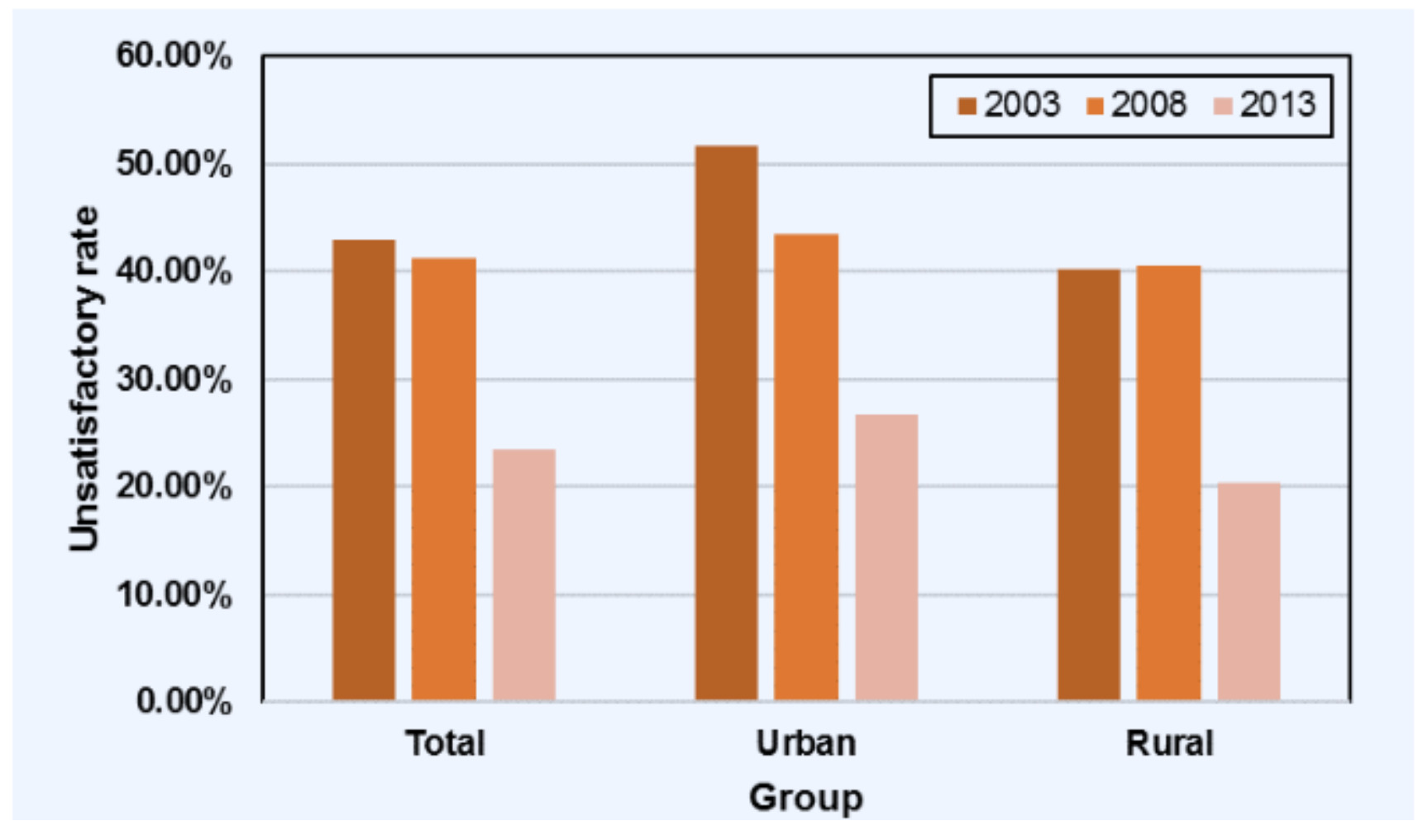

Figure 1

Unsatisfactory rate for the outpatients in 2003,2008 , and 2013 Note: The calculated X2 values for the changes in 2003-2008, 2008-2013, and 2003-2013 are 11.599, 1140.16, and 994.018, and the calculated $P$ values are $0.003,0.000$, and 0.000 , respectively. 


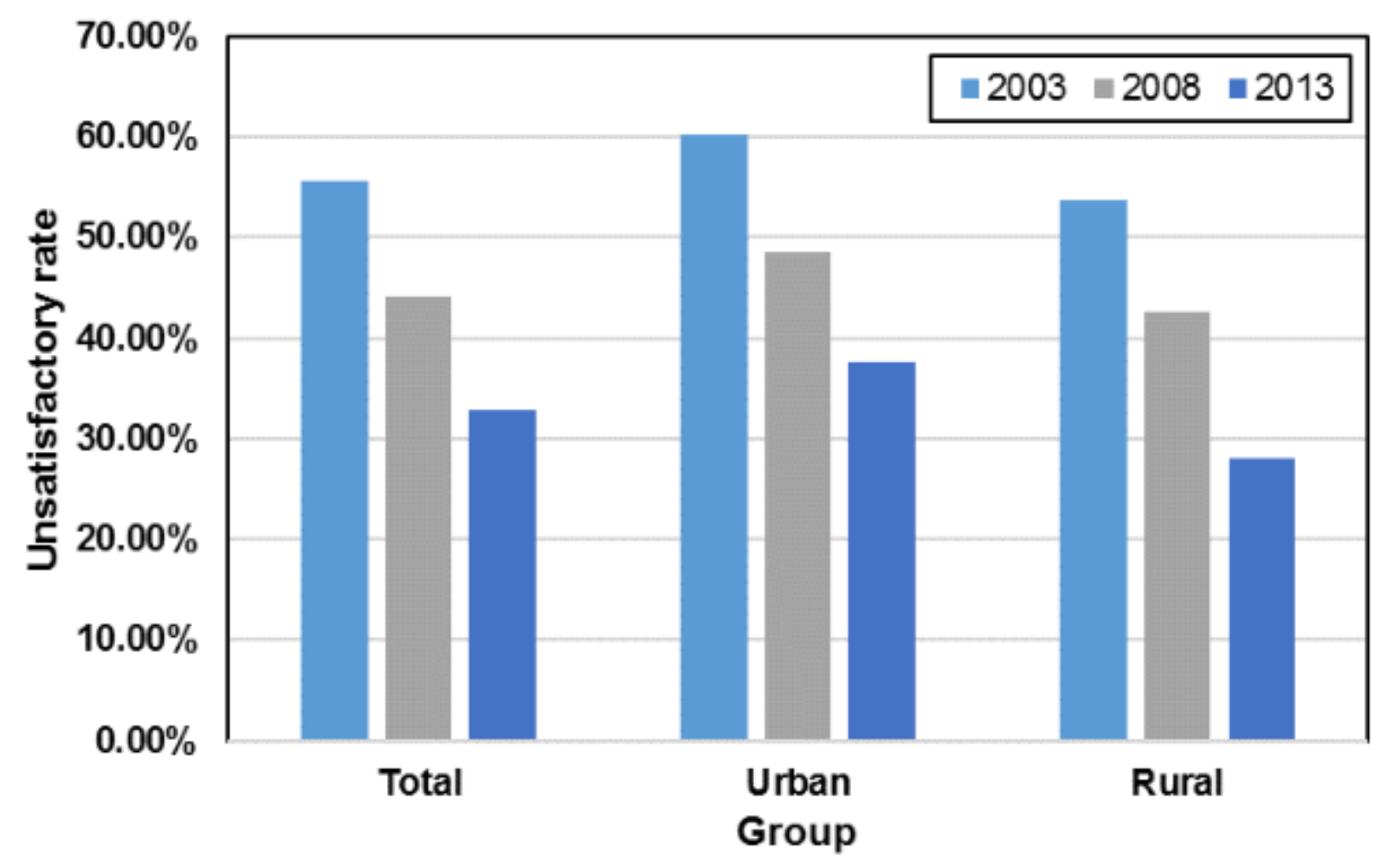

Figure 2

Unsatisfactory rate for the inpatients in 2003, 2008, and 2013 Note: The calculated X2 values for the changes in 2003-2008, 2008-2013, and 2003-2013 are 9.885, 845.875, and 554.186, and the calculated $P$ values are $0.007,0.000$, and 0.000 , respectively. 